\title{
Establishing The Importance Of Japanese Public Infrastructure
}

Radha Balkaransingh, (E-mail: phdpro@yahoo.com), University of Tsukuba, Japan

\begin{abstract}
In an endeavor to get the economy out of its economic slump the Japanese government has proposed several structural reform measures, one of which involves the reduction in public investment spending. We study the soundness of this proposal by investigating both the correlation between public infrastructure and the private sector variables (private output, labour and capital) as well as the causal relationship between public infrastructure and the private variables. Public infrastructure comprises of physical (e.g., roads and ports) and social (e.g., academic institutes) infrastructure. For the first objective we employ the translog production function to determine the nature of the relationship between public infrastructure and the private variables. We find that total public infrastructure (physical plus social) has a positive and significant relationship with private output in the magnitude of $1.03 \%$. Additionally not only do we find that all types of infrastructure impact positively on private sector output but also that social infrastructure had a greater impact on private sector output ( $0.58 \%$ higher). Regarding the second objective we employ the Granger no-causality test procedure developed by Toda and Yamamoto (1995). We establish that public infrastructure Granger causes private labour and private capital. While private capital and private labour Granger cause private output. Also there is a bi-causal relationship between social public infrastructure and private capital. There exists reverse causality between public infrastructure and private output. As such public infrastructure affects private output indirectly through its impact on the private inputs.
\end{abstract}

\section{Introduction}

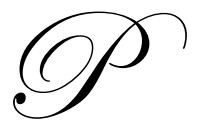

ublic infrastructure has been highlighted as a determinant of growth and it is argued that it has a positive effect on total output and productivity. Aschauer's (1989) seminal paper provoked a vibrant debate on the importance of public infrastructure to growth and productivity. The paper argued that reductions in government spending in public infrastructure precipitated the decline in total factor productivity in the 1970s in the United States. There has been a barrage of research since then. The results range from public infrastructure being positive and significant Aschauer (1989), Mundell (1990) to public infrastructure being inconsequential to the growth process, Tatom (1991) and Hulten and Schwab (1991). There is no universally held view among economists as to the true importance of public infrastructure. There is tremendous controversy surrounding the empirical results. Most of the work done in this area stems primarily from the United States. Recently work has been emerging from Europe: Spain, Italy and Belgium.

If public infrastructure can increase private sector growth and productivity, then growth can be accelerated or stimulated by increased spending on public infrastructure. Otherwise governments can focus on other areas, which promote growth. The objective of this paper is to verify the soundness of the Japanese 2001 proposal to cut spending on public investments by assessing the importance of public infrastructure to the Japanese economy. The change of government in Japan in spring of 2001 brought with it a renewed vigor to get the economy out of its decade long economic slump. Among the various reform plans, the government proposed to resolve banks nonperforming loans and to reduce investments in public spending by $¥ 1$ trillion a year. The proposed cuts are a central pillar of the structural reform of government finances. The Japanese current budget deficit is in the vicinity of $135 \%$

Readers with comments or questions are encouraged to contact the author via email. 
of GDP. It is expected that at present trends, the gross debt will rise more than $200 \%$ by the end of 2005 and $300 \%$ by 2011. So there is no question that the government has to restructure its finances. What we have to question however is the nature of the reform package. One of the main criticisms of this proposal is that reductions in public investments together with the restructuring of the financial sector, would lead to higher levels of unemployment. Japan's unemployment rate reached a record high of 5.8\% in December of 2001. Consequently we also explore the impact of reductions in public infrastructure spending on employment.

It is common practice to use a parametric specification of the production function, such as Cobb-Douglas or translog specification, when production technology is analyzed. In this paper we employ the translog production function specification to examine the correlation between public infrastructure and the private sector variables. The translog production function unlike the Cobb-Douglas production function is a flexible functional form, which does not impose any a priori restrictions on the values of output elasticities, elasticities of substitution, returns to scale or technical change. Establishing correlation however, says nothing about causality. Causal information would serve more useful in policy formulation since knowledge of cause and effect variables would render a more appropriate stimulus package. In determining the nature of causality we utilize the Granger no-causality test procedure developed by Toda and Yamamoto (1995).

The results are in favour of continued investments in all types of public infrastructure with perhaps a greater emphasis on social infrastructure for two reasons. Firstly increased social public infrastructure contributes more to private sector output than physical public infrastructure in the magnitude of $0.58 \%$. Secondly social infrastructure has a bi-causal relationship with private capital, that is private capital investment stimulates and is stimulated by social public infrastructure.

\section{Methodology}

\subsection{The Translog Production Function}

We have assumed in this paper that the production technology in the economy takes the transcendental logarithmic (translog) form as proposed by Christensen et al. (1973). The translog function can be viewed as an approximation of second-order Taylor series of an arbitrary twice differentiable function. Hicks neutrality and symmetry conditions $\left(\beta_{\mathrm{ij}}=\beta_{\mathrm{ji}}\right)$ are imposed a priori. The translog production function can be written as follows:

$\ln \mathrm{Y}=\alpha_{0}+\alpha_{\mathrm{L}} \ln \mathrm{L}+\alpha_{\mathrm{K}} \ln \mathrm{K}+\alpha_{\mathrm{G}} \operatorname{lnG}+1 / 2 \beta_{\mathrm{LL}}(\ln \mathrm{L})^{2}+1 / 2 \beta_{\mathrm{KK}}(\ln \mathrm{K})^{2}+1 / 2 \beta_{\mathrm{GG}}(\operatorname{lnG})^{2}+\beta_{\mathrm{LK}} \ln \mathrm{ln} \mathrm{ln}+\beta_{\mathrm{LG}} \ln \ln \mathrm{ln}+\beta_{\mathrm{KG}} \ln \operatorname{lnG}$

where $\mathrm{L}$ is the total number of hours worked, $\mathrm{K}$ is private sector capital and $\mathrm{G}$ is the stock of public infrastructure ${ }^{1}$.

This formulation is based on the assumption that the private sector maximizes profits (by using private capital and labour) given the stock of public infrastructure and the existing level of technology, which affects both labour and private capital in the same manner (Hicks neutral). The stock of public infrastructure has the embryonic ability to increase the productive capacity of private capital and labour either through the expansion of existing resources or by making more efficient use of resources. We assume that public infrastructure is an unpaid fixed factor of production. This implies that the government finances its expenditure via taxation and provides services directly to the private sector at no cost. Economies of scale may result from the public provision of services. Thus we further assume that the production function exhibits constant returns to scale over the private inputs but increasing returns over all inputs. This assumption is tested.

This brings us to the behavior of the translog production function. In order for the translog production function to be well behaved it has to be homogeneous of degree one in private capital and labour. This therefore implies the following:

$\alpha_{\mathrm{L}}+\alpha_{\mathrm{K}}=1, \quad \beta_{\mathrm{LL}}+\beta_{\mathrm{LK}}=0, \quad \beta_{\mathrm{KK}}+\beta_{\mathrm{LK}}=0, \quad \beta_{\mathrm{KG}}+\beta_{\mathrm{LG}}=0$

The homogeneity of degree one in capital and labour implies that the factor shares of capital and labour

\footnotetext{
${ }^{1}$ See Appendix (A) for the components of public infrastructure.
} 
sum to one:

$\mathrm{S}_{\mathrm{L}}+\mathrm{S}_{\mathrm{K}}=1$

Thus given that the production function is homogeneous of degree one in capital and labour and based on the assumptions of Eq. (2)-(3) we arrive at the following system of equations:

$\mathrm{LnY}-\operatorname{lnL}=\alpha_{0}+\alpha_{\mathrm{K}}(\operatorname{lnK}-\ln \mathrm{L})+\left(\alpha_{\mathrm{G}} \operatorname{lnG}\right)+\beta_{\mathrm{LK}}\left(\operatorname{lnL} \operatorname{lnK}-1 / 2(\operatorname{lnL})^{2}-1 / 2(\operatorname{lnK})^{2}\right)+\beta_{\mathrm{KG}}(\ln \mathrm{K} \operatorname{lnG}-\ln L \ln \mathrm{G})+1 / 2 \beta_{\mathrm{GG}} \ln \mathrm{G}^{2}$

We are able to derive the various private income shares by differentiating the production function with respect to the private inputs:

$\mathrm{S}_{\mathrm{L}}=\partial \ln \mathrm{Y} / \partial \ln \mathrm{L}=\partial \mathrm{Y} / \partial \mathrm{L} * \mathrm{~L} / \mathrm{Y}=\mathrm{P}_{\mathrm{L}} \mathrm{L} / \mathrm{P}_{\mathrm{Y}} \mathrm{Y}=\left(1-\alpha_{\mathrm{K}}\right)+\beta_{\mathrm{LK}}(\ln \mathrm{K}-\ln \mathrm{L})-\beta_{\mathrm{KG}} \ln \mathrm{G}$

$S_{K}=\partial \ln Y / \partial \ln K=\partial \mathrm{Y} / \partial K * K / Y=P_{K} K / P_{Y} Y=\alpha_{K}+\beta_{L K}(\operatorname{lnL}-\ln K)+\beta_{K G} \operatorname{lnG}$

Similarly we can derive the shadow share for public infrastructure as:

$\mathrm{S}_{\mathrm{G}}=\partial \ln \mathrm{Y} / \partial \ln \mathrm{G}=\partial \mathrm{Y} / \partial \mathrm{G} * \mathrm{G} / \mathrm{Y}=\mathrm{Z}_{\mathrm{G}} \mathrm{G} / \mathrm{P}_{\mathrm{Y}} \mathrm{Y}=\alpha_{\mathrm{G}}+\beta_{\mathrm{GG}}(\operatorname{lnK}-\ln \mathrm{L})+\beta_{\mathrm{KG}} \operatorname{lnG}$

Where $\mathrm{Z}_{\mathrm{G}}$ is the shadow price of public infrastructure.

Microeconomic theory requires that the estimated function must satisfy standard homogeneity, monotonicity and concavity conditions. Homogeneity requires that $\mathrm{Y}(\mathrm{t}, \mathrm{L}, \mathrm{K}, \mathrm{G}, \mathrm{A})=\mathbf{t} \mathrm{Y}(\mathrm{L}, \mathrm{K}, \mathrm{G}, \mathrm{A}) \forall \mathrm{t}>0$. In the case of the production frontier, monotonicity requires that the first-order derivative of output with respect to each input be nonnegative, that is:

$\partial \mathrm{Y} / \partial \mathrm{Z}=\mathrm{S}_{\mathrm{Z}} \mathrm{Y} / \mathrm{Z}>0$ where $\mathrm{Z}=\mathrm{L}, \mathrm{K}, \mathrm{G}$

Since $Y>0$, and $Y / Z>0$, the test for monotonicity reduces to $S_{Z}>0$. Thus monotonicity exists when $S_{Z}>0$. Concavity requires that the Hessian matrix of second-order derivatives of output with respect to inputs be negative semidefinite. Violation of any of these properties casts doubt on the ability of the estimated frontier to represent the underlying production technology. We test for these later.

\subsection{Estimation Equation}

The first oil shock in 1973 had a fundamental impact on the Japanese economy and more specifically on the government's fiscal policy. Prior to 1973, the Japanese economy grew at an even rate, this changed after 1973. As such we tested for structural. The Wald test for the hypothesis that the given set of parameters is jointly zero was not accepted. The estimating equations therefore included a dummy and a time variable as a proxy for the structural change in the economy. The system then becomes:

$\mathrm{LnY}-\ln L=\alpha_{0}+\alpha_{\mathrm{K}}(\operatorname{lnK}-\ln \mathrm{L})+\left(\alpha_{\mathrm{G}} \operatorname{lnG}\right)+\beta_{\mathrm{LK}}\left(\ln \mathrm{ln} \mathrm{ln}-1 / 2(\operatorname{lnL})^{2}-1 / 2(\operatorname{lnK})^{2}\right)+\beta_{\mathrm{KG}}(\ln \mathrm{ln} \mathrm{ln}-\ln L \ln \mathrm{g})+1 / 2 \beta_{\mathrm{GG}} \ln \mathrm{G}^{2}+\alpha_{\mathrm{KD}} \mathrm{d}^{*} t *$

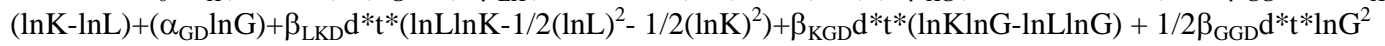

$S_{L}=\left(1-\alpha_{K}\right)+\beta_{L K}(\operatorname{lnK}-\ln L)-\beta_{K G} \operatorname{lnG}+\beta_{L K D} d^{*} t *(\ln K-\ln L)-\beta_{\mathrm{KGD}} \mathrm{d}^{*} \mathrm{t} * \ln G$

where $\mathrm{d}=0$ for $1955-1973$ and $\mathrm{d}=1$ for 1974-1993. $\mathrm{t}$ represents time as a proxy for technical change.

A stochastic error term, which is assumed to be normally distributed with zero expected value and with a positive definite symmetric covariance matrix, is added to Eq. (8) and (9). This system of equations is simultaneously estimated employing the three stage least squares (3SLQ) method. Further we determine the relative elasticities of conditional demand among the variables as follows: 
$\varepsilon_{\mathrm{XG}}=\partial \ln \mathrm{X} / \partial \ln \mathrm{G}=\partial \mathrm{X} / \partial \mathrm{G} * \mathrm{G} / \mathrm{X}=\left(\beta_{\mathrm{XG}}+\mathrm{S}_{\mathrm{X}} \mathrm{S}_{\mathrm{G}}\right) \mathrm{Y} / \mathrm{X}^{2} \mathrm{X}=\mathrm{L}, \mathrm{K}$

$\varepsilon_{\mathrm{LK}}=\partial \ln \mathrm{L} / \partial \ln \mathrm{K}=\partial \mathrm{L} / \partial \mathrm{K} * \mathrm{~K} / \mathrm{L}=\left(\beta_{\mathrm{LK}}+\mathrm{S}_{\mathrm{L}} \mathrm{S}_{\mathrm{K}}\right) \mathrm{Y} / \mathrm{L}^{2}$

This allows us to determine the relationship each variable has with the other variables in the production function. The bias of public infrastructure is determined via the sign of $\varepsilon_{\mathrm{XG}}$. Public infrastructure is factor saving if $\varepsilon_{\mathrm{XG}}<0$ (substitutes), it is factor using if $\varepsilon_{\mathrm{XG}}>0$ (complementary) and neutral if $\varepsilon_{\mathrm{XG}}=0$. Similarly private labour and capital are complements if $\varepsilon_{\mathrm{LK}}>0$, substitutes if $\varepsilon_{\mathrm{LK}}<0$ and neutral if $\varepsilon_{\mathrm{LK}}=0$.

\subsection{Granger Causality}

The standard test for causality is the Granger causality test. The Granger test involves the following vector autoregressive (VAR) model:

$\mathrm{G}_{\mathrm{t}}=\varphi+\sum^{\mathrm{n}}{ }_{\mathrm{i}=1} \mathrm{a}_{\mathrm{i}} \mathrm{X}_{\mathrm{t}-\mathrm{i}}+\sum^{\mathrm{n}}{ }_{\mathrm{j}=1} \mathrm{~b}_{\mathrm{j}} \mathrm{G}_{\mathrm{t}-\mathrm{j}}+\mathrm{u}_{1 \mathrm{t}}$

$X_{t}=\varphi+\sum_{i=1}^{n} c_{i} G_{t-i}+\sum_{j=1}^{n} d_{j} X_{t-j}+u_{2 t}$

where $\mathrm{X}=\mathrm{Y}, \mathrm{L}, \mathrm{K}, \varphi$ is a constant, and $\mathrm{u}_{\mathrm{t}}$ is the error term. The first equation indicates that current $\mathrm{G}$ is related to its own past values as well as those of $X$. Similarly, the second equation implies that current $\mathrm{X}$ is related to its own past values as well as those of G. With respect to causality, X is said to Granger cause $G$ if using past values of X leads to a better prediction of the current value of G. Similarly G is said to Granger cause X if using past values of G leads to a better prediction of the current value of $X$.

Unless the variables in levels are cointegrated the VAR Granger test will lead to spurious regression results, and the F-test is not valid. If variables within the vector autoregressive (VAR) model are not cointegrated, they are run in their first difference. However if they are cointegrated, then the model can be written as an error correction model (ECM), where changes in variables depend on deviations from a long-term equilibrium that is defined by the cointegrating relationship as suggested by Engle and Granger (1987) and the vector auto-regression error-correction model (VECM) as suggested by Johansen and Jesulius, (1990). Unfortunately, these tests are cumbersome and sensitive to the values of the nuisance parameters in finite samples and therefore their results are unreliable (Toda and Yamamoto (1995), Zapata and Rambaldi (1997)). Furthermore, pretests are necessary to determine the number of unit roots and the cointegrating ranks before proceeding to estimate a VECM.

An optional method for testing for Granger causality has been proposed by Toda and Yamamoto (1995). This approach is applicable whether the VAR process is stationary, integrated (of an arbitrary order) or cointegrated (of an arbitrary order). There is no need to address the cointegration properties of the time series. The method involves using a modified Wald test (MWald) for restrictions on the parameters of a $V A R(k)$ (where $\mathrm{k}$ is the lag length in the system). Toda and Yamamoto showed that the test has an asymptotic $\chi_{2}$ distribution when a VAR $\left(k+d_{\max }\right)$ is estimated where $d_{\max }$ is the maximum order of integration that occurs in the system. The test can be carried out without any information on the cointegration properties of the system and the test may be applied when no cointegration exists and/or the stability and rank conditions are not satisfied. All one needs to do is to determine the maximal order of integration $d_{\max }$ which we expect to occur in the model and construct a VAR in their levels with a total of $\mathrm{p}=\left(\mathrm{k}+\mathrm{d}_{\max }\right)$ lags. Toda and Yamamoto point out that, for $\mathrm{d}=1$, the lag selection procedure is always valid since $\mathrm{k} \geq 1=\mathrm{d}$. If $\mathrm{d}=2$, then the procedure is valid unless $\mathrm{k}=1$. Moreover, according to Toda and Yamamoto, the MWald statistic is valid regardless.

Estimation was undertaken using the seemingly unrelated regression (SUR) method. Using the ordinary least squares (OLS) method to independently estimate each equation would give consistent and unbiased estimates. Efficiency however can be improved if the SUR method is employed.

\subsection{Data}

In this paper we employed the index number approach in estimation since we had items measured in hours 
and in value. All the variables were converted into indices. To ensure a consistent basis for estimation we opted for the use of the multilateral index ${ }^{2}$, which allows for more efficient results. The data used were obtained from various Japanese data sources. The primary sources of data were Japanese National Accounts, Historical Statistics of Japan 1955-1985, Japan Statistical Yearbook 1986-1997, and Economic Statistics Annual 1967-1997. See Appendix (B) for an elaboration of the sources and the method of calculation of the various items.

\section{Empirical Analysis}

\subsection{The impact of Public Infrastructure on the Private Sector Variables: Translog Production Function}

The results of the impact of public infrastructure on private output are given in Table 1. There are four time periods, 1955-1993 (I) the entire period which does not account for structural change, 1955-1973 (II) the period prior the change, 1974-1993 (III) the period after the change and finally 1955-1993 (IV) which takes into account the structural change. The regularity condition of convexity holds for all the time periods ${ }^{3}$. Monotonicity however, does not hold for public infrastructure from around the early 1980s (1981-1982) in time periods (I)-(III). In time period (IV) monotonicity is not meet from the late 1980s (1986-1988). Regardless of the imposition of homogeneity restrictions and taking into account the structural changes in time period (IV), we have found that the monotonicity does not hold in the mid 1980s. This means that private sector output is negatively affected by public infrastructure in these years.

\begin{tabular}{|c|c|c|c|c|c|c|c|c|}
\hline \multirow[b]{3}{*}{ Parameter } & \multicolumn{7}{|c|}{ Table 1 The Impact of Public Infrastructure on Private Output } & \\
\hline & \multicolumn{2}{|c|}{$1955-1993(I)$} & \multicolumn{2}{|c|}{ 1955-1973 (II) } & \multicolumn{2}{|c|}{ 1974-1993 (III) } & \multicolumn{2}{|c|}{$1955-1993$ (IV) } \\
\hline & Estimate & t-statistic & Estimate & t-statistic & Estimate & t-statistic & Estimate & t-statistic \\
\hline PPI & 0.14 & 2.14 & 1.02 & 5.21 & 0.20 & 5.43 & 0.90 & 12.75 \\
\hline SPI & 1.08 & 13.0 & 2.45 & 3.91 & 0.21 & 5.32 & 1.48 & 12.35 \\
\hline TPI & 0.37 & 3.73 & 1.26 & 4.89 & 0.20 & 5.47 & 1.03 & 13.04 \\
\hline AIES & & & & & & & 1.55 & 9.15 \\
\hline RDS & & & & & & & 0.93 & 11.61 \\
\hline
\end{tabular}

PPI= Physical Public Infrastructure, SPI= Social Public Infrastructure, TPI= Total Public Infrastructure, AIES=Academic Institutes and the Education System, RDS= Roads

From Table 1 we see the impact of physical (core) infrastructure (PPI) on private sector output. In period (I) we find that a $1 \%$ increase in physical public infrastructure leads to a $0.14 \%$ increase in private sector output. In the period 1955-1973(II), physical public infrastructure has a substantial impact on private output, every $1 \%$ increase in physical public infrastructure leads to a $1.02 \%$ increase in private sector output. Clearly during this time period physical public infrastructure was a major contributor of growth in the Japanese economy. In time period (III) physical public infrastructure is still a positive and significant factor for increasing private output. However it is at a much lower level of $0.20 \%$. Time period (IV) takes into account the change in the economy, which occurred after 1973. In this time period, we find that physical public infrastructure continues to be positive and significant. Physical public infrastructure increases output by $0.90 \%$, the effect of the structural change is a reduction of the positive impact of physical public infrastructure in the magnitude of $0.012 \%{ }^{4}$.

With respect to social public infrastructure (SPI) we immediately notice that in all periods social public infrastructure like physical public infrastructure contributes significantly and positively to the growth of the private sector output. However social public infrastructure does so at a higher rate, when compared with physical public infrastructure. The pattern is similar to that of physical public infrastructure. In the first period when structural change

\footnotetext{
${ }^{2}$ See Caves, Christensen and Diewert (1982) for discussion.

${ }^{3}$ The results of the tests for convexity and monotonicity are available upon request. So too are the goodness of fit tests.

${ }^{4}$ Obtained from the translog estimation.
} 
is not accounted for, we find that social public infrastructure contributes $1.08 \%$ private sector output. Period II shows a significantly high contribution of social public infrastructure. For every $1 \%$ increase in social public infrastructure it leads to a $2.45 \%$ increase in private sector output. Period (III) has a much lower contribution. When structural change is accounted for, social public infrastructure contributes $1.48 \%$ to private sector output. The effect of the structural change is a reduction of the positive impact of social public infrastructure in the magnitude of $0.022 \%$.

Total public infrastructure (TPI) is the combination of social and physical public infrastructure. The result for period (I) is $0.37 \%$ this is in the vicinity of the Aschauer (1989) result of $0.39 \%$. However this result does not take into account the impact of the changes, which occurred in the Japanese economy after 1973. When structural change is accounted for total public infrastructure contributes $1.03 \%$ to private sector output, the effect of the structural change is a reduction of the positive impact of total public infrastructure in the magnitude of $0.014 \%$.

AIES and RDS are the largest component of social and physical public infrastructure respectively. As such we estimate separately these sub-categories to determine their impact on private sector output. In the case AIES, the regularity conditions of monotonicity and convexity are met over the whole period under consideration. Here we find that when structural change is accounted for, AIES contributes $1.55 \%$ to private sector output. The effect of the structural change is a reduction of the positive impact of AIES in the magnitude of $0.022 \%$.

The regularity condition of convexity holds for RDS, however monotonicity does not hold from 1986 . We found that in time period (IV) RDS increases the private sector output by $0.93 \%$. From this we see clearly that AIES contributes significantly more to private sector output than RDS, thus emphasizing again the importance of social public infrastructure over physical public infrastructure.

\begin{tabular}{|c|c|c|c|c|c|c|c|c|}
\hline \multicolumn{9}{|c|}{ Table 2 Testing for Constant Returns to Scale } \\
\hline & \multicolumn{2}{|c|}{ 1955-1993 (I) } & \multicolumn{2}{|c|}{ 1955-73 (II) } & \multicolumn{2}{|c|}{ 1974-1993 (III) } & \multicolumn{2}{|c|}{ 1955-1993 (IV) } \\
\hline & $\chi^{2}$ & P-VALUE & $\chi^{2}$ & P-VALUE & $\chi^{2}$ & P-VALUE & $\chi^{2}$ & P-VALUE \\
\hline PPI & $72.26 *$ & 0.00 & $37.42 *$ & 0.00 & $225.17 *$ & 0.00 & $3.30^{* *}$ & 0.07 \\
\hline SPI & $6.45 *$ & 0.01 & $57.12 *$ & 0.00 & $165.88^{*}$ & 0.00 & $44.60 *$ & 0.00 \\
\hline TPI & $24.84 *$ & 0.00 & $96.43 *$ & 0.00 & $205.69^{*}$ & 0.00 & $13.75^{*}$ & 0.00 \\
\hline AIES & & & & & & & $25.09 *$ & 0.00 \\
\hline RDS & & & & & & & $2.85 * *$ & 0.09 \\
\hline
\end{tabular}

Returns to scale gives us an indication of how the output increases with respect to inputs. As seen in Table 2, we cannot accept the null hypothesis of constant returns to scale (CRTS) for all categories of public infrastructure. Based on the Wald test we reject the null hypothesis of constant returns to scale (CRTS) for all categories of public infrastructure at the 5\% and $10 \%$ levels of significance respectively. We conclude then that there are CRTS to the private sector inputs (labour and capital) and increasing returns to scale (IRTS) over all inputs.

So far we have found that social infrastructure increases private sector output more than physical infrastructure, however over the period 1955-1993, investments in physical infrastructure was significantly higher than investments in social infrastructure. This is a salient factor to be considered in future policy formation. It is important to examine not only the elasticity of public infrastructure (the direct effect) with respect to its impact on the private sector. It is equally important to determine the relationship between public infrastructure and the various private inputs (the indirect effect).

Table 3 contains the various elasticities of conditional demand among the variables (L, K, G). The results reported here, are the overall (1955-1993) mean value of the respective elasticities. We see that the private inputs of capital and labour are complements in the production process. So too are all categories (and sub-categories) of pub- 
lic infrastructure and private capital. All categories (and sub-categories) of public infrastructure and private labour were complements until the late seventies, in the early eighties public infrastructure and private labour became substitutes $^{5}$. The overall result however, is that private labour and all categories (and sub-categories with the exception of AIES) of public infrastructure are substitutes.

Table 3 The Elasticities of Conditional Demand

\begin{tabular}{|c|c|c|c|c|c|c|c|c|c|c|c|c|}
\hline & \multicolumn{2}{|c|}{ TPI } & \multicolumn{2}{|c|}{ PPI } & \multicolumn{2}{|c|}{ SPI } & \multicolumn{2}{|c|}{ AIES } & \multicolumn{2}{|c|}{ RDS } & \multicolumn{2}{|c|}{$\begin{array}{l}\text { Private } \\
\text { Inputs }\end{array}$} \\
\hline & $\varepsilon_{\mathrm{KG}}$ & $\varepsilon_{\mathrm{LG}}$ & $\varepsilon_{\mathrm{KG}}$ & $\varepsilon_{\mathrm{LG}}$ & $\varepsilon_{\mathbf{K G}}$ & $\varepsilon_{\mathrm{LG}}$ & $\varepsilon_{\mathrm{KG}}$ & $\varepsilon_{\mathrm{LG}}$ & $\varepsilon_{\mathrm{KG}}$ & $\varepsilon_{\mathrm{LG}}$ & $\varepsilon_{\mathrm{LK}}$ & $\varepsilon_{\mathrm{KL}}$ \\
\hline Mean & 1.31 & $(0.14)$ & 1.20 & $(0.16)$ & 1.65 & $(0.04)$ & 1.72 & 0.12 & 1.22 & $(0.18)$ & 0.81 & 1.51 \\
\hline Std. Dev & 1.68 & 0.27 & 1.54 & 0.25 & 2.10 & 0.28 & 2.16 & 0.19 & 1.57 & 0.25 & 0.40 & 1.70 \\
\hline
\end{tabular}

It should be noted however, that AIES and labour were complements from 1955-1983. From 1984-1993 labour and AIES have been substitutes. We can conclude then that there is a general substitutive relationship between public infrastructure and labour.

Thus we find that when the stock of public infrastructure increases, the private sector demands less labour and more capital. This has serious implications for employment, since it suggests that increases in public infrastructure decrease the demand for labour. However given that private capital and labour are complements, this means that when the demand for private capital increases so to does the demand for private labour. So while public infrastructure reduces the demand for labour on one hand, through the relationship between private capital and private labour, the demand for private labour increases as public infrastructure increases. Additionally the results here pertain only to private sector labour. Increases in public infrastructure spending may well increase the demand for government sector workers, leading to an overall increase in total employment.

\subsection{The Causal Nature of Public Infrastructure: Toda and Yamamoto (1995) Granger Causality Test}

Tables 4-6 contain the results for the Granger no-causality tests for the entire period 1955-1993 not accounting for structural change. Causality is determined via the asymptotic $\chi_{2}$ distribution with degree of freedom $\mathrm{p}$ $(k+d)$. We present the results for two cases of VAR (p); VAR (3) (d=1 and k=2), and VAR (4) (d=2 and k=2).

There are four possible patterns of causality which we may find: (1) uni-directional causality from public infrastructure to the private variables; (2) uni-directional causality from the private variables to public infrastructure (reverse causation); (3) a bi-directional causal relationship where the private variables cause public infrastructure and public infrastructure causes the private variables; (4) and finally there can be no causality. The nature of the causal relationship will have policy implications as to whether or not there should be reductions in investments in public infrastructure.

Table 4 provides us with the results of the test of no causality between public infrastructure and the private sector variables. $\mathrm{H}_{\mathrm{o}}$ : public infrastructure does not cause the various private sector variables. Columns 1,2 and 3 contain the Wald test statistic with the corresponding $\mathrm{p}$-value in parenthesis to determine whether public infrastructure causes private output, private capital and private labour respectively.

\footnotetext{
${ }^{5}$ A similar result was found for the United States by Pereira and Flores (1999)
} 


\begin{tabular}{|c|c|c|c|}
\hline \multicolumn{4}{|c|}{$\begin{array}{l}\text { TABLE } 4 \text { Granger Causality Test } \\
\text { Wald test 1955-1993 }\end{array}$} \\
\hline & \multicolumn{3}{|c|}{ VAR (3) } \\
\hline $\mathrm{G} \rightarrow \mathrm{Y}, \mathrm{L}, \mathrm{K}$ & 1 & 2 & 3 \\
\hline Dependent variable & LY & LK & LL \\
\hline LG1 & $2.2(0.14)$ & $1106.2(0.00)$ & $1810.0(0.00)$ \\
\hline LG2 & $0.76(0.38)$ & $932.0(0.00)$ & $1256.0(0.00)$ \\
\hline LG3 & $8.2(0.00)$ & $1847.2(0.00)$ & $926.0(0.00)$ \\
\hline LAIES & $14.2(0.00)$ & $2063.0(0.00)$ & $576.0(0.00)$ \\
\hline \multirow[t]{2}{*}{ LRDS } & $0.149(0.97)$ & $684.5(0.00)$ & $873.0(0.00)$ \\
\hline & \multicolumn{3}{|c|}{ VAR (4) } \\
\hline LG1 & $7.87(0.00)$ & $920.9(0.00)$ & $1441.0(0.00)$ \\
\hline LG2 & $4.66(0.03)$ & $743.6(0.00)$ & $911.8(0.00)$ \\
\hline LG3 & $1.28(0.26)$ & $1461.7(0.00)$ & $821.2(0.00)$ \\
\hline LAIES & $2.28(0.13)$ & $1521.6(0.00)$ & $569.0(0.00)$ \\
\hline LRDS & $1.30(0.25)$ & $455.2(0.00)$ & $601.0(0.00)$ \\
\hline
\end{tabular}

We first examine whether public infrastructure causes private sector output. For VAR (3) at all levels of significance $(1 \%, 5 \%, 10 \%)$, the null hypothesis of no causality is accepted with the exception of social infrastructure and its subcomponent AIES. For social infrastructure and its subcomponent AIES we reject the null hypothesis and conclude that they Granger cause private output. In the case of VAR (4) we again accept the null hypothesis of no causality however, here the exception is total public infrastructure. At all levels of significance we cannot accept the null hypothesis of no causality for total public infrastructure. We conclude that total infrastructure Granger causes private sector output. The direction of causality vis-à-vis public infrastructure and private output is sensitive to the lag length employed in the analysis. Unless an appropriate lag length is stipulated we cannot make any precise conclusion based on these contradicting results.

The results for the private inputs labour and capital (columns 2 and 3) are the same regardless of the lag length (VAR (3), VAR (4)) and the level of significance (1\%, 5\% 10\%). We reject the null hypothesis of no causality between public infrastructure and the private inputs and conclude that public infrastructure (all categories and sub-categories) Granger cause the private inputs, labour and capital. These results are not sensitive to the lag length as such we can positively construe that all categories of public infrastructure Granger cause the private inputs.

In Table 5 we examine the results of $\mathrm{H}_{0}$ : the private sector variables do not cause public infrastructure. Here the test is for reverse causation. Columns 1,2,3,4, and 5 contain the respective Wald test statistic with the corresponding $\mathrm{p}$-value in parenthesis. It is important to recognize at the out set that the results presented in Table 5, are insensitive to the lag length, this ensures consistency of the results for both VAR (3) and VAR (4).

So we find that regardless of the lag length and the level of significance, private output Granger causes all categories and sub-categories of public infrastructure. In the case of private capital, we cannot reject the null hypothesis of no Granger causality between private capital and public infrastructure for both VAR (3) and VAR (4). Once again, the exception is social infrastructure and its subcomponent AIES. At all levels of significance we reject the null hypothesis that social infrastructure and its subcomponent AIES do not Granger cause public infrastructure. 


\begin{tabular}{|c|c|c|c|c|c|}
\hline \multicolumn{6}{|c|}{ Table 5 Granger Causality Test -Wald Test 1955-1993 } \\
\hline \multicolumn{6}{|c|}{$\operatorname{VAR}(3)$} \\
\hline $\mathrm{Y}, \mathrm{L}, \mathrm{K} \rightarrow \mathrm{G}$ & 1 & 2 & 3 & 4 & 5 \\
\hline Dependent variable & LG1 & LG2 & LG3 & LAIES & LRDS \\
\hline LY & $75.6(0.00)$ & $68.8(0.00)$ & $312.2(0.00)$ & $685.4(0.00)$ & $141.4(0.00)$ \\
\hline LK & $20.8(0.15)$ & $1.38(0.24)$ & $8.77(0.00)$ & $10.36(0.00)$ & $6.92(0.01)$ \\
\hline LL & $2.42(0.12)$ & $3.30(0.07)$ & $1.85(0.17)$ & $2.50(0.12)$ & $5.35(0.02)$ \\
\hline \multicolumn{6}{|c|}{ VAR (4) } \\
\hline & LG1 & LG2 & LG3 & LAIES & LRDS \\
\hline LY & $59.3(0.00)$ & $61.2(0.00)$ & $182.1(0.00)$ & $348.4(0.00)$ & $150.1(0.00)$ \\
\hline LK & $3.04(0.08)$ & $1.67(0.20)$ & $10.8(0.00)$ & $13.1(0.00)$ & $5.35(0.02)$ \\
\hline LL & $3.43(0.06)$ & $3.23(0.07)$ & $1.87(0.17)$ & $2.95(0.09)$ & $3.93(0.05)$ \\
\hline
\end{tabular}

With respect to labour we again establish that regardless of the lag length and the level of significance we cannot reject the null hypothesis of no Granger causality between private labour and public infrastructure. There is no evidence of a bi-causal relationship between labour and public infrastructure. Causality is uni-directional and it runs from public infrastructure to private labour.

Table 6 presents the results of the examination of the causal relationship between the various private sector variables. We verify that there is only uni-directional causality from the private sector inputs of labour and capital to private sector output, regardless of the lag length and the level of significance. Private sector inputs precede private output. This implies that anything, which increases private sector inputs, would by extension lead to increases in private output.

\begin{tabular}{lcc}
\hline \multicolumn{3}{c}{$\begin{array}{c}\text { Table 6 Granger Causality Test } \\
\text { Wald Test 1955-1993 }\end{array}$} \\
\hline & VAR (3) & VAR(4) \\
K,L $\rightarrow$ Y & 1 & 2 \\
Dependent Variable & LY & LY \\
LK & $\mathbf{4 3 1 . 9 ( 0 . 0 0 )}$ & $\mathbf{3 4 8 . 7}(\mathbf{0 . 0 0})$ \\
LL & $\mathbf{1 6 9 . 2 ( 0 . 0 0 )}$ & $\mathbf{1 3 9 . 8}(\mathbf{0 . 0 0})$ \\
& & \\
Y $\rightarrow$ K,L & & \\
Dependent Variable & LK & LL \\
VAR (3) & & \\
LY & $0.93(0.33)$ & $0.208(0.65)$ \\
& & \\
VAR (4) & & \\
LY & $0.53(0.47)$ & $0.015(0.90)$ \\
\hline
\end{tabular}


Based on the results of Tables 4 and 5 we can corroborate the robustness of the relationship between the private inputs and public infrastructure. The pattern of causality remained constant as the VAR lags changed. We have found that there is uni-directional causality between private labour and public infrastructure, where public infrastructure Granger causes private labour. In the case of private capital there exists a uni-directional relationship with physical infrastructure and its component RDS. That is physical infrastructure and its component RDS Granger causes private capital and not vice versa. With respect to private capital and social infrastructure and its component AIES, we found bi-directional causality for both VAR (3) and VAR (4).

As recognized earlier the results regarding the causal relationship between public infrastructure and private output are sensitive to the lag length employed. As such it is essential to identify the appropriate lag length to allow a decisive conclusion. We thus tested the variables for the order of integration and found that the maximum lag length to be 2 and that the maximum order of integration of the variables is 1 (based on the unit roots tests). As such we refer to the results of VAR (3). In this regard at all levels of significance we conclude that there exists bidirectional causality between social infrastructure and its subcomponent AIES and private output. With respect to the physical infrastructure category and its subcomponent RDS, there exists uni-directional reverse causation i.e. private output Granger causes physical infrastructure and not vice versa. We now deliberate the impact that structural change would have on these results.

\subsection{The impact of structural change}

As noted from the Wald test in the translog section, the Japanese economy experienced structural changed after the first oil crisis. Consequently we tested the period before and after 1973 to determine the impact of structural change on the causal relationship between the private variables and public infrastructure. We did not conduct causality tests for the whole period, 1955-1993, taking into accounting structural change, since we find that doing would not clearly indicate the true nature of causality that existed before 1973. Robustness of the results is ensured if consistency in is achieved in both time periods. The causality results for the period before and after the oil shock are presented in Tables 7-12. For the reasons given above we discuss only the VAR (3) results.

According to Table 7, during the period 1955-1973, none of the categories of public infrastructure Granger caused private sector output. The same holds for the period 1974-1993, we see from Table 8 that no type of public infrastructure Granger causes private output. This does not compare with the results for the entire period. If we consider that accounting for structural change facilitates a more realistic analysis of the economy then we can conclude that public infrastructure does not Grange cause private output at all levels of significance.

In both time periods all categories of public infrastructure Granger cause the private inputs. This can be seen in columns 2 and 3 of Tables 7-8. This result is consistent with the results for the entire period. We can safely conclude then that variations in investments in public infrastructure will have a direct impact on the utilization of private inputs by firms. Structural change did not alter the causal relationship between public infrastructure and the private inputs.

Table 7 Granger Causality Test -Wald test 1955-1973

\begin{tabular}{lccc}
\hline & \multicolumn{3}{c}{ VAR $(3)$} \\
$\mathrm{G} \rightarrow \mathrm{Y}, \mathrm{L}, \mathrm{K}$ & 1 & 2 & 3 \\
Dependent variable & $\mathrm{LY}$ & $\mathrm{LK}$ & $\mathrm{LL}$ \\
$\mathrm{LG} 1$ & $0.84(0.36)$ & $\mathbf{6 3 . 6 0 ( 0 . 0 0 )}$ & $\mathbf{2 0 2 . 4 ( 0 . 0 0 )}$ \\
LG2 & $0.13(0.72)$ & $\mathbf{1 1 3 . 0}(\mathbf{0 . 0 0})$ & $\mathbf{1 5 6 . 7 ( 0 . 0 0 )}$ \\
LG3 & $3.71(0.05)$ & $\mathbf{1 9 3 . 2 ( 0 . 0 0 )}$ & $\mathbf{3 5 4 . 0}(\mathbf{0 . 0 0})$ \\
LAIES & $4.24(0.04)$ & $\mathbf{5 3 4 . 4 ( 0 . 0 0 )}$ & $\mathbf{3 1 0 . 0}(\mathbf{0 . 0 0})$ \\
LRDS & $0.24(0.88)$ & $\mathbf{1 8 5 . 4 ( 0 . 0 0 )}$ & $\mathbf{1 1 6 . 0}(\mathbf{0 . 0 0})$ \\
\hline
\end{tabular}




\begin{tabular}{lccc}
\hline \multicolumn{4}{c}{ Table 8 Granger Causality Test -Wald test $\mathbf{1 9 7 4 - 1 9 9 3}$} \\
\hline \multicolumn{4}{c}{ VAR (3) } \\
G $\rightarrow$ Y,L,K & 1 & 2 & 3 \\
Dependent variable & LY & LK & LL \\
LG1 & $2.41(0.12)$ & $\mathbf{1 5 0 . 0}(0.00)$ & $\mathbf{7 2 . 1 ( 0 . 0 0 )}$ \\
LG2 & $4.68(0.03)$ & $\mathbf{1 7 4 . 0 ( 0 . 0 0 )}$ & $\mathbf{3 8 . 8 ( 0 . 0 0 )}$ \\
LG3 & $0.38(0.98)$ & $\mathbf{8 9 . 0 ( 0 . 0 0 )}$ & $\mathbf{1 4 3 ( 0 . 0 0 )}$ \\
LAIES & $0.85(0.77)$ & $\mathbf{1 0 0 . 0}(0.0)$ & $\mathbf{1 1 9}(0.00)$ \\
LRDS & $3.36(0.07)$ & $\mathbf{9 3 . 0 0 ( 0 0 )}$ & $\mathbf{4 1 . 8 ( 0 . 0 0 )}$ \\
& & & \\
\hline
\end{tabular}

The test for reverse causation is presented in Tables 9-10. In Table 9 we find that prior to the oil shock, private sector output Granger caused all categories of public infrastructure. With respect to capital there existed a bidirectional causal relationship between private capital and social infrastructure. In the case of labour there existed bidirectional causality between labour and all categories of infrastructure with the exception of AIES. The labour results differ significantly from the 1955-1993 period.

\begin{tabular}{|c|c|c|c|c|c|}
\hline \multicolumn{6}{|c|}{ Table 9 Granger Causality Test -Wald Test 1955-1973 } \\
\hline \multicolumn{6}{|c|}{ VAR (3) } \\
\hline $\mathrm{Y}, \mathrm{L}, \mathrm{K} \rightarrow \mathrm{G}$ & 1 & 2 & 3 & 4 & 5 \\
\hline Dependent variable & LG1 & LG2 & LG3 & LAIES & LRDS \\
\hline LY & $10.86(0.00)$ & $8.40(0.00)$ & 47.47(0.00) & $74.0(0.00)$ & $20.12(0.00)$ \\
\hline LK & $1.53(0.22)$ & $1.07(0.30)$ & $14.65(0.00)$ & $0.93(0.33)$ & $2.39(0.12)$ \\
\hline LL & $14.75(0.00)$ & $14.80(0.00)$ & $8.95(0.00)$ & $6.16(0.13)$ & $16.88(0.00)$ \\
\hline \multicolumn{6}{|c|}{ Table 10 Granger Causality Test -Wald Test 1974-1993 } \\
\hline \multirow[t]{2}{*}{$\mathrm{Y}, \mathrm{L}, \mathrm{K} \rightarrow \mathrm{G}$} & & VAR (3) & & & \\
\hline & 1 & 2 & 3 & 4 & 5 \\
\hline Dependent variable & LG1 & LG2 & LG3 & LAIES & LRDS \\
\hline LY & $16.87(0.00)$ & $10.82(0.00)$ & 47.13(0.00) & $83.16(0.00)$ & $25.0(0.00)$ \\
\hline LK & $5.69(0.02)$ & $5.43(0.02)$ & $6.59(0.01)$ & $6.32(0.01)$ & $1.32(0.25)$ \\
\hline LL & $0.05(0.83)$ & $0.102(0.75)$ & $0.15(0.70)$ & $0.16(0.69)$ & $0.018(0.89)$ \\
\hline
\end{tabular}

In Table 10, for the period 1974-1993, causality again runs from private sector output to all categories of public infrastructure. In this period there exists a bi-directional relationship between private capital and social infrastructure and its sub component AIES. Labour does not cause any type of public infrastructure. In this latter period 
1974-1993 the results are the same as the total period 1955-1993 in Table 5.

\begin{tabular}{lc}
\hline & $\begin{array}{c}\text { Table 11 Granger Causality Test } \\
\text { Wald Test 1955-1973 }\end{array}$ \\
\hline & VAR (3) \\
K,L $\rightarrow$ Y & 1 \\
Dependent Variable & LY \\
LK & $\mathbf{3 3 . 6 ( 0 . 0 0 )}$ \\
LL & $\mathbf{2 8 . 9 ( 0 . 0 0 )}$ \\
Y $\rightarrow$ K,L & \\
Dependent Variable & \\
VAR (3) & LK \\
LY & \\
VAR (4) & \\
LY & $4.94(0.03)$ \\
\hline
\end{tabular}

Table 12 Granger Causality Test 1974-1993

\begin{tabular}{lc} 
& VAR (3) \\
K,L $\rightarrow$ Y & 1 \\
Dependent Variable & LY \\
LK & $\mathbf{1 0 0 . 8 ( 0 . 0 0 )}$ \\
LL & $\mathbf{1 2 . 3 9 ( 0 . 0 0 )}$ \\
Y $\rightarrow$ K,L & \\
Dependent Variable & LK \\
VAR (3) & \\
LY & $0.79(0.37)$ \\
VAR (4) & \\
LY & $0.57(0.45)$ \\
\hline
\end{tabular}

Tables 11-12 take into account the causal relationship between the private sector variables over the period 1955-1973 and 1974-1993 respectively. In both Tables private capital and labour Granger cause private output. There is only uni-directional causality from the private variables to private output. This result is consistent with the result of the overall period. As in the case of public infrastructure and the private inputs, structural change did not alter the causal relationship between private output and the private inputs.

The relationship between public infrastructure and the private inputs (labour and capital) remain generally consistent in spite of the structural change and lag length considered. However the direct relationship between private output and public infrastructure changes with the lags and when structural change is taken into account. When we take into account the impact of structural change in the economy, we conclude that private output unidirectionally causes public infrastructure. The existence of reverse causation does not imply that public infrastructure has no impact on private output, since all categories of public infrastructure Granger cause the private inputs. 
The private inputs in turn Granger cause private output, and it is through this relationship that public infrastructure influences private output. More importantly it has a direct impact on the level of employment and private capital accumulation.

\section{Conclusion}

In this paper we employed the translog production function to determine the relationship between public infrastructure and the various private sector variables from 1955-1993. We found a positive and significant relationship between private sector output and all categories and sub-categories of public infrastructure. Additionally, not only do we find that all types of public infrastructure positively affect private sector output, but also that social infrastructure has a greater impact on private sector output when compared with physical infrastructure. This is contrary to the view that physical infrastructure is more important for stimulating growth in the private sector.

The results found here differ in both in terms of the size and type of infrastructure. Firstly few papers have found such a high elasticity for public infrastructure and secondly most papers have found that physical infrastructure is more important for the growth process. Here we have found that while physical infrastructure is important for the growth process, social infrastructure is even more important in Japan.

We have also established that public infrastructure and private capital were complements over the period considered. However public infrastructure and private labour have an overall substitutive relationship, this implies that increases in public infrastructure spending leads to higher levels of private unemployment. There are two points to note here first that this does not mean that total unemployment would increase, since it is expected that increases in public investments in infrastructure would increase the demand for public workers as such we may expect that as public infrastructure increases, total employment would also increase. Secondly the complementary relationship between private capital and public infrastructure, and private capital and private labour, lead to an indirect increase in the demand for private labour when public infrastructure increases.

Additionally we investigated the nature of the causal relationship between public infrastructure and the various private inputs using the Granger no-causality test procedure developed by Toda and Yamamoto (1995). We again investigated the period 1955-1993. Additionally we examined the impact of structural change, which occurred in 1973, the period of the first oil crisis. The findings of the paper support the need for continued public infrastructure spending, since we found that all categories of public infrastructure cause private labour and private capital. Robustness of the results is ensured as they are consistent regardless of the lag length and the period considered. We verified that the private inputs uni-directionally caused private output and we found that private output unidirectionally caused public infrastructure. Increases in public infrastructure then have direct implications for employment and private investments and indirect implications for private output.

Private capital and social public infrastructure and its sub-component AIES have a bi-directional causal relationship. AIES comprises namely academic institutes and the school system. This implies that funding for research and development as well as improving the school system would result in greater efficiency for the private sector. This highlights the importance of human capital development in Japan.

Japan's educational system has been unbeaten at turning out the workers its industry has needed in the past. But now it is widely regarded as being in trouble, since it needs to reform to develop graduates who can innovate, not just conform. Recently there has been growing criticism that schools are not providing the human resources necessary for economic growth. In a way, education is taking the flak for the protracted economic slump. The need for bold educational reform is obvious. "Without educational reform, we will not be able to generate new economic growth," says Kokei Higuchi, vice president of the Japan Business Federation ${ }^{6}$. The results found here would be in favour of educational reform since we have found that AIES has a significant impact on private sector output.

If we recognize that academic institutes incorporates not only universities but also government research in-

\footnotetext{
${ }^{6}$ Taken from Asahi 08/08/02
} 
stitutes then we can make the connection between AIES and private capital. The objective of academic institutes is namely research and development $(R \& D)$. R\&D implies improvements and innovations, which are usually applied to the private sector. This translates into investment in new technology for the private sector. R\&D expenditures by all major Japanese industry sectors have been at best level and have been decreasing repeatedly since the early 1990s (National Science Foundation NSF (1995)). It should be noted, however, that while Japan's ratio of R\&D to GDP is the highest in the world, its ratio of government funded R\&D is lowest in the developed countries (Hay ashida 1996). There is therefore room for improvement in AIES funding.

Overall then we see that there is indeed a role for public infrastructure investment in Japan more specifically, there is a great role for social infrastructure. We have found that public infrastructure can serve as a catalyst for growth. Actual evidence however has shown that public infrastructure has not helped to spur growth in the Japanese economy. The catalytic nature of public infrastructure may have been inhibited due to sub-optimal allocation, mismanagement of public funds and inefficiency in the use of public infrastructure. These are all issues, which require further investigation. Notwithstanding these possible limitations, based on the results found here, the policy recommendation would be to continue investments in all types of public infrastructure with greater emphasis on social infrastructure namely AIES.

\section{References}

1. Aschauer, D.A., (1989), "Is Public Expenditure Productive?", Journal of Monetary Economics, 23, 177-200.

2. Evans P. Karras G., (1994), "Are Government Activities Productive? Evidence from a Panel of U.S States", The Review of Economics and Statistics, Vol. LXXVI No. 1, 1-11.

3. Everaert G., and Heylen F., (2001), "Public capital and productivity growth: Evidence for Belgium, 19531996", Economic Modelling 18, 97-116.

4. Hayashida, H., 1996. Science 272 (14 June).

5. Hulten, C.R. and R.M. Schwab, (1991b), "Public Capital Formation and the Growth of Regional Manufacturing Industries", National Tax Journal, 44, 121-134.

6. Lynde C and Richmond J., (1992), "The Role of Public Capital in Production”, The Review of Economics and Statistics, 37-44.

7. Lynde C. and Richmond J (1993), "Public Capital and Total Factor Productivity", International Economic Review Vol. 34, No.2, 401-414.

8. Mackinnon J.G., (1991) Critical values for co-integration tests in R.F Engle and C.W Granger(Eds.), Longrun Economic relationships. Oxford University Press, 267-76.

9. Moreno R., Lopez-Bazo E., Artis M., (2002). Public infrastructure and the performance of manufacturing industries: short- and long run effects. Regional Science and Urban Economics 32, 97-121.

10. Morrison C.J and Schwartz A.E., (1996) "State Infrastructure and Productive Performance", The American Economic Review Vol. 86, No.5,1095-1111.

11. Munnell, A.H. and Cook L.M., (1990), "How Does Public Infrastructure Affect Regional Economic Performance", in: A.H. Munnell, editor, Is There a Shortfall in Public Capital Investment? Federal Reserve Bank of Boston, Boston.

12. Nemoto J, Kamada K, and Kawamura M., (1999), "Estimates of optimal public capital stocks in Japan using a public investment discount rate framework", Empirical Economics, 24:693-710.

13. NSF. (U.S. National Science Foundation), Tokyo Office. 1995. Report Memorandum \#95-22 (quoting statistics published by the Statistics Bureau, Management and Coordination Agency, Government of Japan)

14. Pereira A.M, Oriol R.S (2001), "Infrastructures and total performance in Spain", Journal of Policy Modeling, 23 371-384.

15. Pereira A.M and Flores de Frutos Rafael, (1999), "Public Capital Accumulation and Private Sector Performance", Journal of Urban Economics, 46, 300-322.

16. Toda HiroY., Yamamoto Taku, (1995). Statistical inference in vector autoregressions with possibly integrated process. Journal of Econometrics 66, 225-250.

17. Tatom, J.A. (1991), "Public Capital and Total Performance", Federal Reserve Bank of St. Louis Review, 73, 3-15.

18. Zapata H.O. and Rambaldi A.N., 1997. Monte Carlo evidence on cointegration and causation. Oxford Bulletin of Economics and Statistics 59, 285-298. 


\section{Appendix}

\section{(A) Defining Public Infrastructure}

Physical (Core) Infrastructure (PPI): Ports, Roads (RDS), Subway, Airports, Postal Service, Sewage System, All Waste Water System, Industrial Water system

Social (Environmental/Other) Infrastructure (SPI): $\quad$ City Parks, Academic Institute and School System (AIES), Education and Sports, Afforestation, Seashore Development

Total Public Infrastructure (TPI): PPI + SPI

\section{(B) Data Elaboration}

Private Sector Output: (The pivate sector output was determined via the OECD formula for calculating Private GDP as given in their Business Sector Data Base, here it is determine via the expenditure side) Gross Domestic Expenditure Less Government Final Consumption Less Gross fixed capital by the Public Sector Less Increase in stock by public enterprises Equals Private sector GDE=GDP

Private Labour/Employment Total Employment Less Government Employees (National and Local Government) Equals Private sector labour

Labour hours Worked was calculated as: Private labour x Average Hours worked (monthly) x 12;

Private Sector Capital Economic Planning Agency (EPA)

Public Infrastructure Toyoeizai Shinposha (1998)

\section{All Other Variables}

Variable

GDP Deflator

PCF Deflator

Real Gross Private Capital Stock

Private Fixed Capital Consumption

Average Interest Rate on loans and discounts

Corporate (Basic) Income Tax Rate

Private Fixed Capital Consumption

Depreciation Rate for private capital

Unit User cost of capital

Depreciation Rate for public infrastructure

\section{Calculation}

GDPDEF

PCFDEF

RPK

PFCC

IR IR

CTR CTR

PFCC

DEPPK (PFCC/GDPDEF)/RPK (mean value 0.086582)

UPK $\quad((\mathrm{PCFDEF} / \mathrm{GDPDEF}) *(\mathrm{IR}+\mathrm{DEPPK}) / 1-\mathrm{CTR}$

DEPPI $0.0792^{*}$

*Calculation based on Nemoto et al. (1999). The depreciation rate of public infrastructure would be smaller than that of the depreciation of private capital since public infrastructure is more durable than the privately owned capital. 
Notes 